MODELING, IDENTIFICATION AND CONTROL, 1990, VOL. 11, NO. 4, 181--190

doi:10.4173/mic.1990.4.1

\title{
Density driven currents in the Barents Sea calculated by a numerical model
}

\author{
DAG SLAGSTAD $\dagger$, KJELL STØLE-HANSEN $\dagger$ \\ and HARALD LOENG $\ddagger$
}

Keywords: Hydrodynamical model, simulation, Barents Sea.

\begin{abstract}
A baroclinic, 3-D model is described. It is adapted to a Barents Sea situation in order to simulate the currents in this area. The model is of a so-called level type which contains fixed, but permeable levels. It also includes thermodynamics which allow freezing and melting of ice. Using density data obtained during the autumn of 1988 , a current pattern, driven by density and bottom topography is simulated. No wind is applied. The simulated current pattern gives an overall picture which is similar to what is observed through the few measurements that are available. Good agreements with the observations is found on the Svalbard bank, Tromsøflaket and along the Novaya Zemlya Coast. In the Bear Island/Hopen depth the model predicts a large eddy which has not been observed. Several smaller, topographical steared eddies are seen in the eastern part of the model area.
\end{abstract}

\section{Introduction}

There are three main water masses in the Barent Sea, which are related to different current systems: The Norwegian Coastal current, the Atlantic current, and the Arctic current system. According to Helland-Hansen and Nansen (1909) the Atlantic water is defined by salinity above 35.0 . The temperature is above $4^{\circ} \mathrm{C}$ at the entrance to the Barents Sea, gradually decreasing eastwards. The Coastal water has almost the same temperature as the Atlantic water, but is characterized by lower salinity. The Arctic water has temperatures usually below $-1^{\circ} \mathrm{C}$ and salinity between 34.4 and 34.8 (Loeng 1988). During summer, ice melting creates low saline surface water in the northern part and, in south, increased river runoff decreases the density of the Coastal water. During winter, ice freezing and low runoff increase the salinity and accordingly the density in Arctic and Coastal water, respectively.

Only the general features of the circulation pattern are well known. Earlier descriptions of the circulation were mainly based on the distribution of temperature and salinity in different depth layers, and a few current measurements. Agenerov (1946) studied the available current observations, and both Tantsiura (1959) and Novitskiy (1961) made a comprehensive analysis of the currents of the Barents Sca. The current niap shown in Fig. 1 is based on this work, but a lot of corrections have been made especially in the south-western part. These are made on the basis of current measurements carried out mainly during the last 10 years and recent hydrographical observations. The map shows that there are two main current directions. In the

Received I September 1990.

$\dagger$ SINTEF Automatic Control, 7034 Trondheim, Norway.

¥Institute of Marine Research, Bergen, P.O. Box 1870 Nordnes, 5024 Bergen, Norway. 


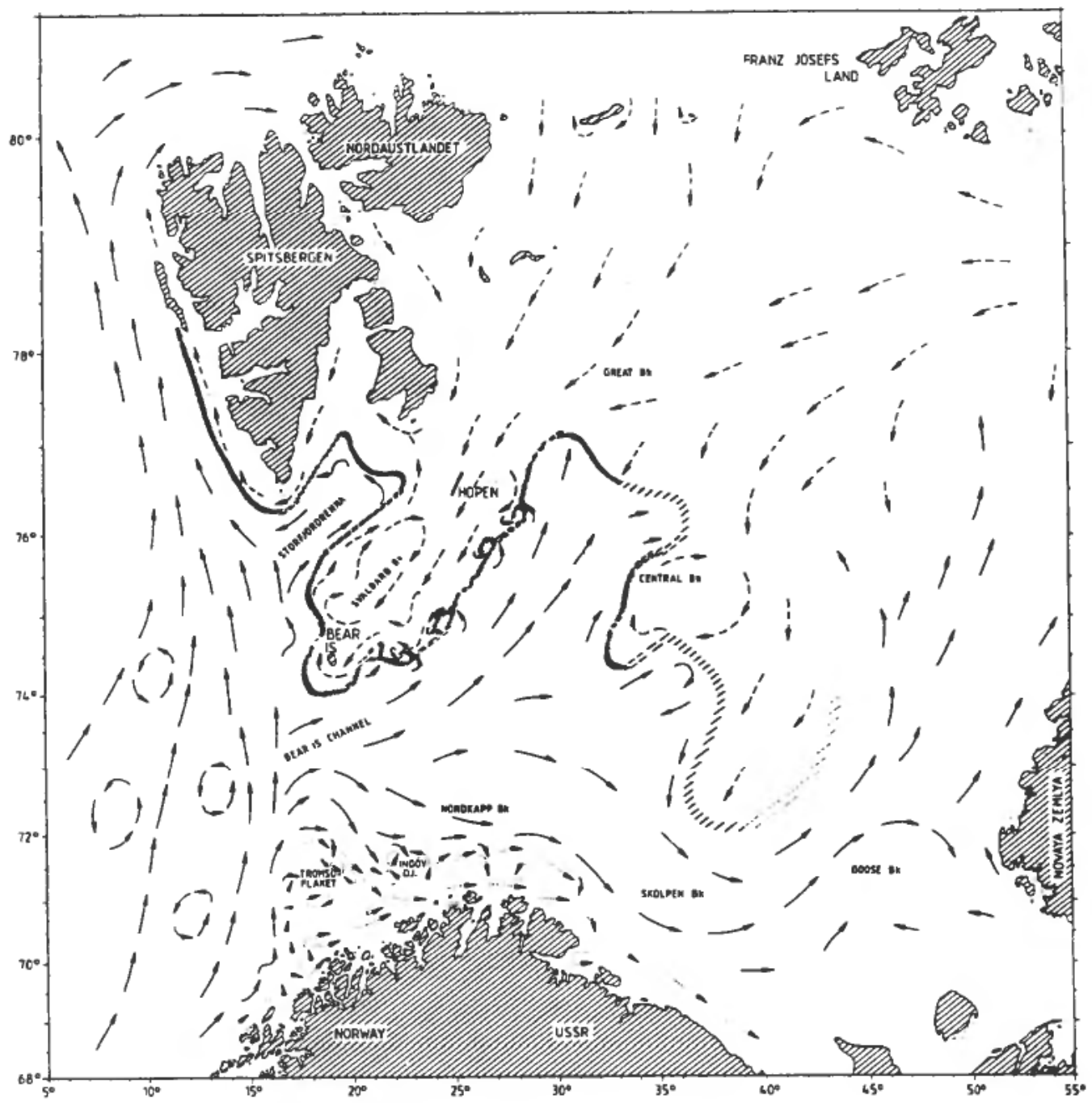

Figure 1. Surface currents in the Barents Sea, based on hydrographical data and current measurements. $(\longrightarrow)$ Atlantic currents, $(\cdots \rightarrow)$ Coastal currents and $(--\rightarrow)$ Arctic currents. From Loeng 1988.

southern part the currents are towards the east, while in the north the Arctic water flows in the opposite direction. The details of the current system are, however, still poorly known. Using a numerical model, we hope to reveal some details in the water circulation and, in addition point out where to make new current measurements.

The density structure indicates that a numerical model of the Barents Sea must be of a baroclinic type. This has been confirmed through simulations with a depth integrated model which gave a current pattern very different to what has been observed (Slagstad 1987). The present paper describes a 3-dimensional, baroclinic model developed at SINTEF, Trondheim and tested against hydrographical and current data from the Institute of Marine Research, Bergen. 


\section{Model equations}

The equations describing motion of water on a rotating earth, incorporating horizontal and vertical diffusion of momentum can be written:

Velocity in $x$-direction

$$
\frac{\partial u}{\partial t}=f v-u \frac{\partial u}{\partial x}-v \frac{\partial u}{\partial y}-w \frac{\partial u}{\partial z}-\frac{1}{\rho} \frac{\partial p}{\partial x}+A_{H} \nabla^{2} u+\frac{\partial}{\partial z} A_{V} \frac{\partial u}{\partial z}
$$

Velocity in $y$-direction

$$
\frac{\partial v}{\partial t}=-f u-v \frac{\partial v}{\partial y}-u \frac{\partial v}{\partial x}-w \frac{\partial v}{\partial z}-\frac{1}{\rho} \frac{\partial p}{\partial y}+A_{H} \nabla^{2} u+\frac{\partial}{\partial z} A_{V} \frac{\partial v}{\partial z}
$$

Vertical velocity is found from the equation of continuity

and surface elevation

$$
\frac{\partial w}{\partial z}+\frac{\partial u}{\partial x}+\frac{\partial v}{\partial y}=0
$$

$$
\eta=\int w d t
$$

where

$u, v$ horizontal velocity components in $x$ - and $y$-direction, respectively

$w$ vertical velocity component

$\eta$ height of the free surface from the undisturbed mean

$f$ Coriolis parameter

$\rho$ density

$A_{H}$ horizontal eddy diffusion of momentum

$A_{V} \quad$ vertical eddy diffusion of momentum

$p$ pressure found by the equation

$$
p=\int_{z}^{0} \rho g d z
$$

The space-time variations of water density, $\rho$, are found by the functional relationship

$$
\rho=\rho(S, T)
$$

where $S$ and $T$ are the salinity and temperature of water, respectively. These scalar fields are modeled by a balance equation in the form

$$
\frac{\partial c}{\partial t}=-\frac{\partial}{\partial x}(u c)-\frac{\partial}{\partial y}(v c)-\frac{\partial}{\partial z}(w c)+K_{H} \nabla^{2} c+\frac{\partial}{\partial z}\left(K_{V} \frac{\partial c}{\partial z}\right)
$$

where $c=S$ or $T$ and the operator $\nabla^{2}$ means

$$
\nabla^{2} \Theta=\frac{\partial^{2} \Theta}{\partial x^{2}}+\frac{\partial^{2} \Theta}{\partial y^{2}}
$$

$\Theta$ is any function of $x$ and $y . K_{H}$ and $K_{V}$ are horizontal and vertical eddy diffusion, respectively, of temperature and salinity.

Most ocean basins are often more or less stratified with horizontal dimensions much larger than the vertical dimension. A three-dimensional, finite-difference model can be visualized as a leveled model defined by a sequence of fixed, but permeable, 


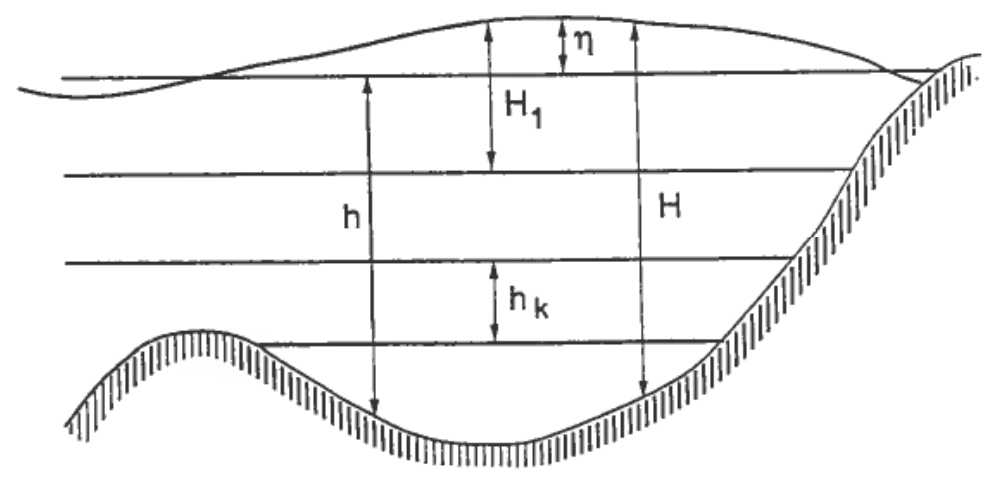

Figure 2. Vertical configuration of the multi-level model. The notation used is $H$ is the total depth from the undisturbed surface. $h_{k}$ is the thickness of level number $k . H_{k}$ is the time variable thickness of level number $k$.

levels. In this work the levels are taken to be horizontal. Each level has a fixed thickness except the level near the surface and the level that happens to be near the bottom. Thus, the number of levels will be a function of the horizontal coordinates. The present version of the model has ten levels $(10,15,20,25,30,50,50,100,100,100 \mathrm{~m})$. The horizontal grid point distance is $20 \mathrm{~km}$.

A multi-level model can be derived by integrating eqns. (1) and (2) over the depth interval representing one level. We then obtain depth integral models which are, in a way stacked on top of each other. The time derivatives of flow in $x$ - and $y$-directions for level no. $k$ are

$$
\begin{aligned}
\frac{\partial U_{k}}{\partial t}= & f V_{k}-H_{k} u_{k} \frac{\partial u_{k}}{\partial x}-H_{k} v_{k} \frac{\partial u_{k}}{\partial y}-H_{k} w_{k} \frac{\partial u_{k}}{\partial z} \\
& -\frac{H_{k}}{\rho} \frac{\partial p}{\partial x}+H_{k} \frac{\partial}{\partial z}\left(A_{V} \frac{\partial u_{k}}{\partial z}\right)+H_{k} A_{H} \nabla^{2} u_{k}+S B_{k}^{x} \\
\frac{\partial V_{k}}{\partial t}= & -f U_{k}-H_{k} v_{k} \frac{\partial v_{k}}{\partial y}-H_{k} u_{k} \frac{\partial v_{k}}{\partial y}-H_{k} w_{k} \frac{\partial v_{k}}{\partial z} \\
& -\frac{H_{k}}{\rho} \frac{\partial p}{\partial y}+H_{k} \frac{\partial}{\partial z}\left(A_{V} \frac{\partial v_{k}}{\partial z}\right)+H_{k} A_{H} \nabla^{2} v_{k}+S B_{k}^{y}
\end{aligned}
$$

The vertical velocity is calculated from the equation of continuity

$$
w_{k}=w_{k+1}-\left(\frac{\partial U_{k}}{\partial x}+\frac{\partial V_{k}}{\partial y}\right)
$$

The surface elevation is found by integrating the vertical velocity of the air-sea interface, $w_{1}$

$$
\begin{aligned}
& \frac{\partial \eta}{\partial t}=w_{1} \\
& U_{k}=\int_{-z_{k}}^{z_{k-1}} u d z \quad V_{k}=\int_{z_{k}}^{z_{k-1}} v d z
\end{aligned}
$$

and $u_{k}=U_{k} / H_{k}$ and $v_{k}=V_{k} / H_{k} \cdot z_{k}$ is the distance from the undisturbed surface to the interface between level $k$ and $k+1$, and $z_{0}$ is equal to $\eta$. 
$S B_{k}$ is the wind and bottom stress which only applies to the surface and bottom levels, respectively

$$
S B_{k}=\left\{\begin{array}{lll}
\tau_{s} & \text { for } & k=1 \\
0 & \text { for } & 1<k<K \\
-\tau_{b} & \text { for } & k=K
\end{array}\right.
$$

where $K$ is the deepest level.

In a shallow part of the model area it may happen that the surface and bottom levels are the same, then

$$
S B_{1}=\tau_{s}-\tau_{b}
$$

The bottom stress, $\tau_{b}$, is calculated explicitly by a quadratic formulation

$$
\tau_{b}=c_{d}|\boldsymbol{V}| \boldsymbol{V}
$$

where $\boldsymbol{V}=[u, v]^{\mathrm{T}}$.

\subsection{Vertical mixing}

We assume that the vertical eddy diffusion coefficient is a function of the vertical buoyancy gradient, only. The following relationship is assumed

$$
A_{V}, K_{V}=\left\{\begin{array}{lr}
A_{\mathrm{mx}}-\alpha_{A} \frac{d b}{d z} & 0<\frac{d b}{d z} \leqslant 2 \times 10^{-4} \\
A_{\mathrm{mn}} & \frac{d b}{d z}>2 \times 10^{-4}
\end{array}\right.
$$

where

$A_{\mathrm{mx}}$ maximum vertical eddy diffusion when the buoyancy gradient is zero

$A_{\mathrm{mn}}$ minimum vertical eddy diffusion when there is a strong buoyancy gradient

$\alpha_{A}$ parameter calculated as

$$
\alpha_{A}=\frac{A_{\mathrm{mx}}-A_{\mathrm{mn}}}{2 \times 10^{-4}}
$$

$b$ buoyancy calculated as

$$
b=-g \frac{\rho_{0}-\rho}{\rho_{0}}
$$

The parameter values are

$$
\begin{aligned}
A_{\mathrm{mn}} & =1.0 \times 10^{-4} \mathrm{~m}^{2} \mathrm{~s}^{-1} \\
A_{\mathrm{mx}} & =300 \times 10^{-4} \mathrm{~m}^{2} \mathrm{~s}^{-1} \\
\rho_{0} & =1027.5 \mathrm{~kg} \mathrm{~m}^{-3}
\end{aligned}
$$

\subsection{Numerical approximation}

The equations of momentum and continuity are solved using a finite difference technique similar to that of Tingele et al. (1979). The state variables are discretized in space on a staggered grid known as Arakawa $\mathbf{C}$ grid. Central differencing is used in space whereas a two-level, semi-implicit scheme is used in time. Advection of temperature and salt is approximated by a second order upstream scheme. More details can be found in Slagstad (1987). 


\subsection{Mode splitting}

In order to increase computer efficiency a mode splitting technique, not unlike the one described by Berntsen et al. (1981) is used. The horizontal velocity vector $v$ is decomposed into the vertical average value $\boldsymbol{V}$ and a deviation from the mean value $\hat{\boldsymbol{v}}$

$$
\boldsymbol{v}=\boldsymbol{V}+\hat{\boldsymbol{v}} \text { and } \boldsymbol{V}=\frac{1}{H} \int_{-h}^{\eta} \hat{\boldsymbol{v}} d z
$$

where $H=\eta+$ h.

A complete description can be found in Berntsen et al.(1981). The finite differencing technique is, however, different from their leap-frog scheme.

At the open boundaries, the Sommerfeld radiation condition is used (Orlanski 1976).

\section{Simulation results}

The model area and the bottom topography are shown in Fig. 3. The western boundary is closed. At the southern boundary a constant input velocity of $10 \mathrm{~cm} \mathrm{~s}^{-1}$ is applied for the Norwegian Atlantic Current increasing to $30 \mathrm{~cm} \mathrm{~s}^{-1}$ close to the shore in the Coastal current, depending on the density gradient between the Coastal and the Atlantic waters. Between Nordaustlandet and Franz Josef Land a weak inflow equal to $2 \mathrm{~cm} \mathrm{~s}^{-1}$ at the surface is assumed near Nordaustlandet (Aagaard et al. 1983),

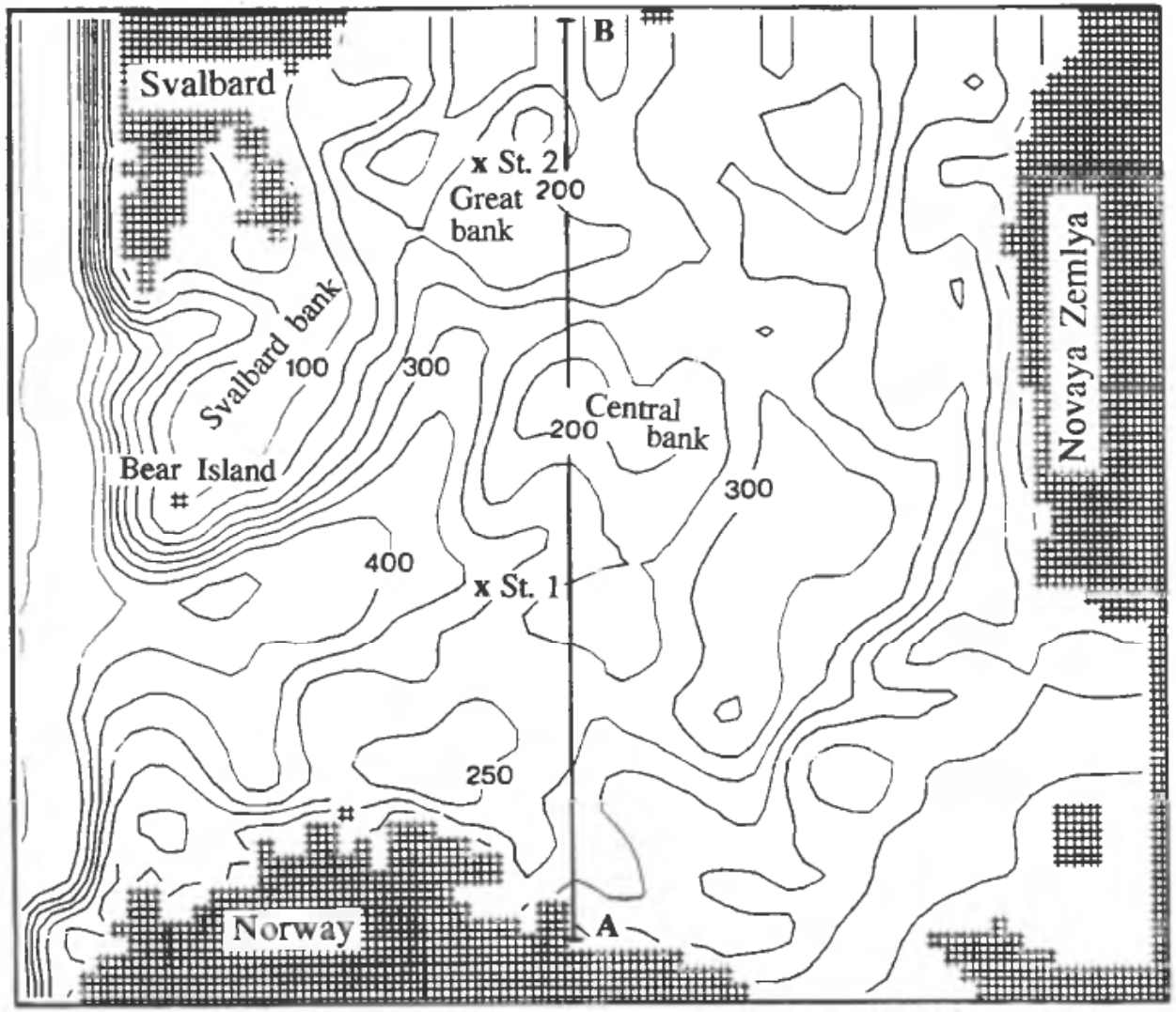

Figure 3. Bottom topography of the model area. An isobath is shown for every $50 \mathrm{~m}$. 


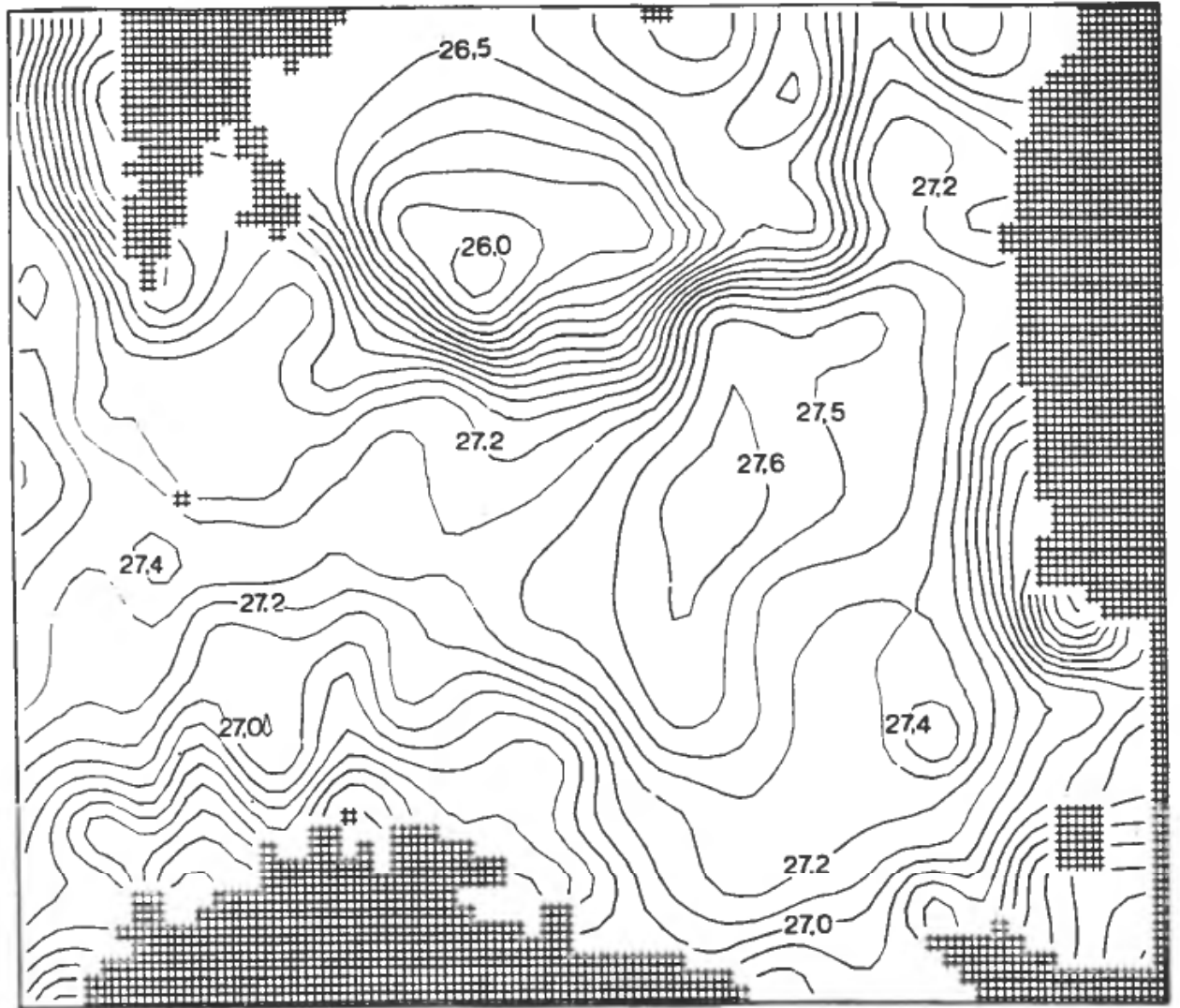

Figure 4. Density field $\left(\sigma_{t}\right)$ at the surface used in the simulation run.

decreasing to zero near Franz Josef Land. In deeper layers, flow will be a function of the density gradient. Between Franz Josef Land and Novaya Zemlya the surface is adjusted to allow an outflow of $2 \mathrm{~Sv}\left(2 \times 10^{6} \mathrm{~m}^{3} \mathrm{~s}^{-1}\right)$.

The density field (Fig. 4) is based on measurements from 590 hydrographical stations carried out during the autumn 1988 . There is no data available north of $78^{\circ} \mathrm{N}$. For this area we have used data from 1979 and interpolated between the data sets. This is possible because usually there are relatively small variations in the hydrographical regime in that area. The low density in the north, especially above the Great bank, is due to ice melting.

The simulated surface currents (Fig. 5) have features which are quite similar to the current map constructed by observations (Fig. 1), but there are also some profound differences.

The Coastal current and the Norwegian Atlantic current divide into two separate branches on the south-western slope of Tromsøflaket. One branch follows the coast and has velocities of 15 to $20 \mathrm{~cm} \mathrm{~s}^{-1}$. The second branch continues northwards along the western slope of the bank, enters the Barents Sea in the Bear Island channel and moves south-east along the eastern slope of Tromsøflaket. The two branches reunite again near the coast of Finnmark. The velocities here are great, 50 to $60 \mathrm{~cm} \mathrm{~s}^{-1}$. This is in very good accordance with the results from drifting experiments (Loeng and Sundby 1989). 


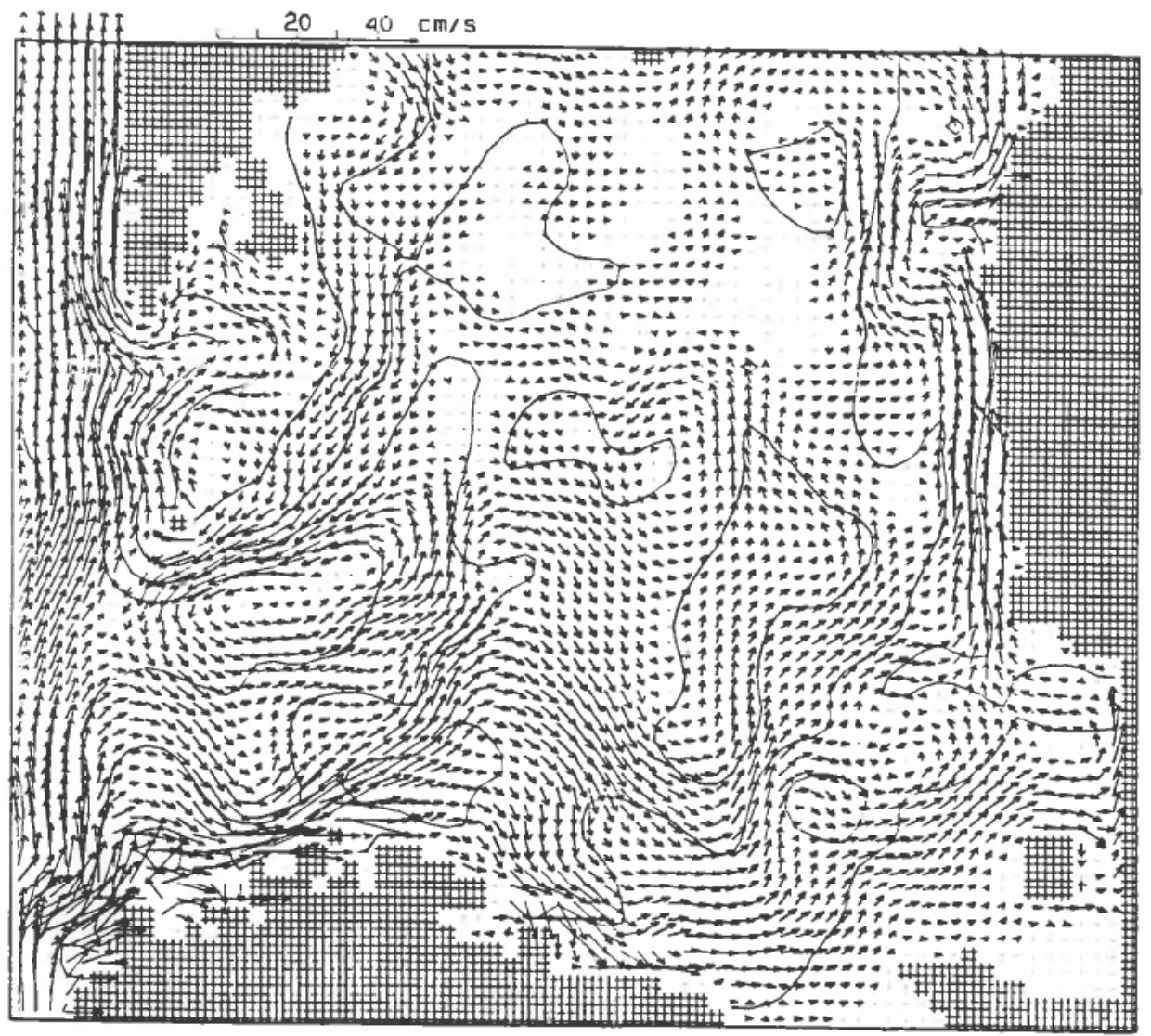

Figure 5. Simulated, density-driven surface currents in the Barents Sea. Velocities less than $1 \mathrm{~cm} \mathrm{~s}^{-1}$ are indicated by a dot.

On the eastern slope of Ingøydjupet there is a current leaving the coast. This current, which is confirmed by drifting buoys (Loeng and Sundby 1989) may be important for transport of eggs and larvae from the spawning grounds near the coast.

In the Bear Island/Hopen depth there seems to be a great eddy which is insensitive to change in inflow and outflow at the northern boundary. The available data do not show clear signs of this current pattern. If this eddy is real, it will certainly affect the residence time of planktonic animals in the area.

On the Svalbard Bank there is a permanent eddy which probably is of great importance in order to keep the pelagic stages of the bottom animals within the area. The hydrographical data and drifting buoys all confirm this eddy (Loeng et al. 1987).

The east-going current, north of the Murman Coast (USSR), is strongest at the slope between $200-300 \mathrm{~m}$. This current continues along the coast of Novaya Zemlya and can be observed from surface temperature maps as a branch of relatively high temperature penetrating an area with colder waters.

Near the bottom, in the level between 200 and $300 \mathrm{~m}$, the currents (Fig. 6) are quite similar to the surface currents, except in the Bear Island/Hopen depth where the eddy is less pronounced. This would certainly be different if we had applied wind stress on the surface (Ådlandsvik 1989). 


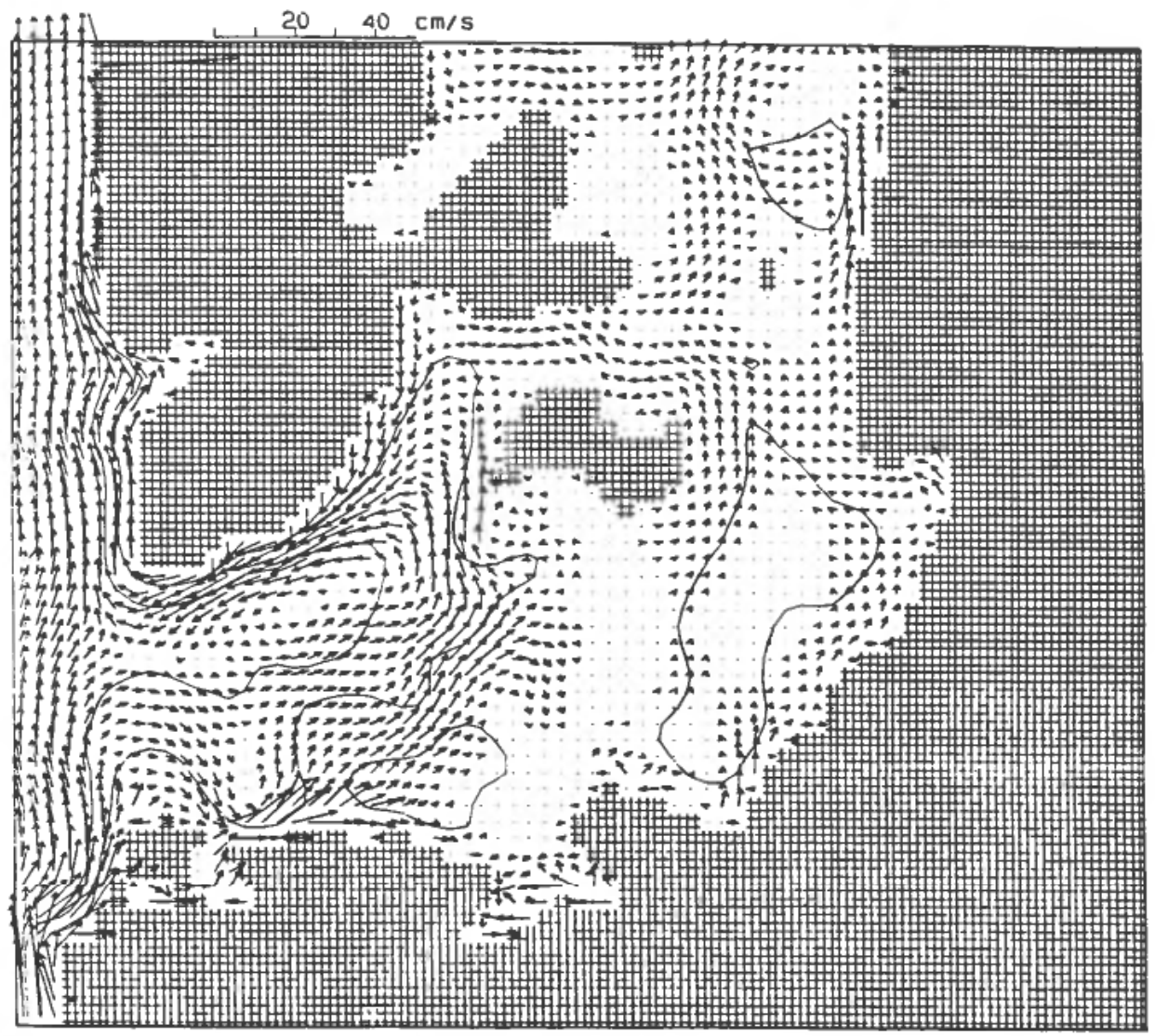

Figure 6. Simulated, density driven currents between 200 and $300 \mathrm{~m}$. Velocities less than $1 \mathrm{~cm} \mathrm{~s}^{-1}$ are indicated by a dot.

The hydrographical data indicates that there is an east-going current near the bottom in the channel between the Central bank and the Great bank. The simulated current has the opposite direction. Sensitivity analysis has shown that it is possible to get an east-going current by manipulating the amount of water that is allowed to flow out in the north-east. However, this gives an unrealistic current pattern in the whole northern part of the model area. Previous simulation runs (unpublished) have indicated that winter cooling may produce an east-going current in this channel. A possible explanation is that the water masses on the Central bank are, during the summer, partly replaced by relatively saline water of Atlantic origin. This water has a greater potential to become denser when cooled than the water masses on the Great bank which have lower salinity. The density gradient which then arises may produce an east-going current during the winter time.

The simulated current pattern in the northern part of the model area is uncertain due to lack of density data and more or less unknown boundary conditions. This emphasizes the need for current measurements both at the northern and eastern boundaries of the Barents Sea. Sensitivity analysis has shown that the currents in the southern part are relatively independent of the boundary conditions in the north. The currents in the south are governed by the density field and the bottom topography. 
ACKNOWLEDGMENTS

This work was supported financially by the Norwegian Fisheries Council (NFFR) through the Norwegian Research Program for Marine Arctic Ecology (PRO MARE).

\section{REFERENCES}

AagaArd, K., Foldvik, A., Gammelsrød, T. and Vinje, T. (1983). One year records of current and bottom pressure in strait between Nordaustlandet and Kvitøya, Svalbard, 1980-81. Polar Research, 1, n.s., 107-113.

ÅDLANDSVIK, B. (1989). Wind-driven variations in the Atlantic inflow to the Barents Sea. Coun. Meet. Int. Coun. Explor. Sea (C: 18), 1-12.

AGENERov, V. K. (1946). On the dynamics of the Barents Sea water. Gidrometeozdat. $130 \mathrm{pp}$.

Berntsen, H., Kowalik, Z., Saelid, S. and Sørli, K. (1981). Efficient numerical simulation of ocean hydrodynamics by a splitting procedure. Modeling, Identification and Control, 2, 181-199.

Helland-Hansen, B. and NAnsen, F. (1909). The Norwegian Sea. FiskDir. Dkr. Ser. HavUnders, 2 (2), 1-360.

LOENG, H. (1988). The influence of climate on biological conditions in the Barents Sea. NAFO Scient. Coun. Meet. Doc. 88/83: 1-19.

LoENG, H., ReY, F. and SkJOLdal, H. R. (1987). Physical and biological oceanographical features across the Polar front in the western Barents Sea. Contribution to the 22nd. European Marine Biology Symposium 17-22 August 1987, Barcelona, Spain.

LOENG, H. and SunDBY, S. (1989). Drifting Argos buoys in the Barents Sea. Coun. Meet. Int. Coun. Explor. Sea $(C: 19)$.

NovitskIY, V. P. (1961). Permanent currents of the northern Barents Sea. Trudy Gos Okeanogr. Inst., 64, 1-32 (in Russian).

ORLANSKI, I. (1976). A simple boundary condition for unbounded hyperbolic flows. Journal of Computational Physics, 21, 251-269.

SlaGsTaD, D. (1987). A 4-dimenstional physical model of the Barents Sea. SINTEF Report STF 48 F87013, 1-34.

Tantsiura, A. I. (1959). About the currents in the Barents Sea. Trudy Polyar. Nauchno-issled. Inst. Morsk. Ryb. Knoz. Okeanogr., 11, 35-53 (in Russian).

Tingele, A. G., Dieterle, D. A. and Walsh, J. J. (1979). Perturbation analysis of the New York Bight. In R. J. Livingston, (ed.). Ecological Processes in Coastal and Marine Systems (Plenum Press, New Yorl), pp. 395-435. 